\title{
MEDIAÇÃO E CONCILIAÇÃO - UM ESTUDO SOBRE AAPLICABILIDADE NA SEGUNDA UNIDADE DOS JECC DA COMARCA DE FORTALEZA
}

\author{
Carlos Henrique Garcia de Oliveira \\ Mestre em Direito (UFC). Professor da curso de Direito da FA7. Juiz \\ de Direito em Fortaleza (CE). \\ professorcarloshenriqueoliveira@hotmail.com
}

Sumário: Introdução. 1. Mediação. 2. Mediação incidental e mediação parajudicial. 3. Conciliação. 4. Distinção entre Mediação e Conciliação. 5. O aprimoramento da Justiça Estadual - a mediação e a conciliação na Segunda Unidade do Juizado Especial Cível e Criminal. Considerações finais. Referências.

\begin{abstract}
Resumo: O presente ensaio se presta a demonstrar um breve estudo sobre os institutos da Mediação e da Conciliação, bem como sua efetiva aplicabilidade na Segunda Unidade dos Juizados Especiais Cíveis e Criminais da Comarca de Fortaleza de Entrância Especial do Estado do Ceará. A pesquisa de campo feita no juizado em epígrafe avaliou a viabilidade, adoção e aplicação dos métodos alternativos de solução de conflitos no âmbito do Poder Judiciário, haja vista que evidencia uma mudança nos padrões tradicionais de solução de conflitos, ao mesmo tempo em que se reconhece e valoriza a eficácia dos métodos alternativos de solução de conflitos, também conhecidos como MASCS. Reconhecemos a atividade exercida pelo Conselho Nacional de Justiça, no que pertine à aplicabilidade dos MASCS no âmbito do Poder Judiciário, tendo como portal de acesso os Juizados Especiais. Demonstramos as estatísticas do referido Juizado, quanto à Mediação - recentemente implantada com sucesso bem como, quanto a Conciliação, situação em que já vem obtendo um excelente percentual de acordo, que implica também no descongestionamento da justiça. Ao final, alertamos que, não obstante todos os esforços, é necessário que não se confundam - Mediação com Conciliação - e que haja realmente uma mudança nos paradigmas da Justiça.
\end{abstract}

Palavras-chave: Mediação. Conciliação. Métodos alternativos de solução de conflitos. Juizados Especiais. 


\section{INTRODUÇÃO}

O trabalho menciona tema de diversas outras áreas do direito (material e processual), sem, contudo, discuti-los ou esgotá-los. Quando propõe a adoção de uma política nacional de incentivo aos mecanismos para obtenção da autocomposição, deixa claro que tem por escopo mostrar a importância dos institutos da mediação e da conciliação, bem como a prejudicial fungibilidade entre os mesmos. Ocupamos-nos em estudar a aplicabilidade e eficácia da lei $\mathrm{n}^{\mathrm{o}}$ 9.099/95 no que tange à conciliação, utilizando como parâmetro o Juizado Especial da Segunda Unidade localizado no Bairro da Maraponga, em Fortaleza-Ceará.

Da mesma maneira que a temática sobre mediação e conciliação abordada neste breve estudo é relativamente recente no mundo jurídico pátrio. Igualmente ocorre com os juizados especiais no âmbito federal e estadual. Muitos desconhecem a sistemática e funcionalidade dos juizados especiais, e de certo modo da mediação e conciliação. Portanto, a conciliação, a mediação e os juizados especiais estão presentes nestas discussões interagindo como tema.

O estado do Ceará implantou o Sistema de Juizados Especiais Cíveis e Criminais mediante a criação da Lei $\mathrm{n}^{\circ} 12.553$, datada de 27 de dezembro de 1995, que trata da sua organização, composição e competência. Os Juizados Especiais são oriundos dos Juizados de Pequenas Causas, e que posteriormente receberam esta nova denominação melhor apropriada. Em Fortaleza existem vintes unidades de juizados especiais distribuídas em bairros.

A opção pelo estudo sobre Mediação e da Conciliação no âmbito do Juizado Especial estadual se deu em virtude do alcance geográfico na área de Fortaleza, o que faz com que atenda mais diretamente a população. Concentramos nosso estudo de campo na Segunda Unidade do Juizado Especial Cível e Criminal.

\section{Mediação}

O vocábulo mediação provém do latim mediare que significa estar no meio, que exprime um conceito de neutralidade do mediador. Quando devido à natureza do impasse, quer seja por suas características ou pelo nível de envolvimento emocional das partes, fica bloqueada a negociação, há a inclusão informal ou formal de terceiro imparcial na negociação ou na disputa ocorre o evento chamado mediação.

A mediação informal ocorre no dia a dia em variadas situações, desde a interferência de parentes e amigos até a de líderes comunitários e religiosos. São mecanismos informais, sem estrutura, sem destinação exclusiva. Seguem métodos intuitivos, sem reflexão, baseados no bom senso e experiência de vida, fortalecidos pelo conhecimento que o mediador informal normalmente tem dos 
envolvidos e do próprio problema (embora esse conhecimento possa constituir-se em vício para a mediação, quando a aproximação quotidiana dos envolvidos com o mediador retira-lhe o caráter de imparcialidade).

Por outro lado, paulatinamente, vem surgindo a mediação como um mecanismo formal, estruturado, fortalecido por técnicas e teorias, estudado por inúmeras ciências (como ocorre com a negociação). A mediação, que se mantinha, no entanto, como atividade não jurídica, distante das regras processuais e das técnicas da conciliação, vem passando por uma institucionalização, por meio de Projetos de Lei e Provimentos . No entanto, pela experiência e observação, no Juizado Especial da $2^{\mathrm{a}}$ Unidade de Fortaleza - Ceará há muito se percebe que é perfeitamente possível a realização desse instituto, desde que observados e preservados os princípios basilares da mediação, vindo a ser inclusive recomendado em determinadas situações, como por exemplo, nos conflitos de vizinhança, de condomínio, escolas, ações freqüentes nos Juizados Especiais.

A mediação não possui formas rígidas, mas sua realização profissional é caracterizada por métodos elaborados e comprovados com rigor científico. Suas principais características são: a cooperação, a autocomposição, a confidencialidade, a ênfase no futuro e a economia de dinheiro, tempo e energia.

Entretanto, o mediador não é um mero assistente passivo, mas sim um modelador de ideias. Ele lança mão de técnicas especiais e com habilidade escuta as partes, as interroga, apaga o problema, cria opções e tem como escopo, que as partes cheguem à sua própria solução do conflito, isto é autocomposição. É fundamental conscientizar as partes de que no dia a dia são elas e somente elas, quem deverão conviver com aquela determinada situação e que, por essa razão a solução deverá partir das vontades dos envolvidos. Por isso o mediador não expressa sua opinião sobre o resultado do pleito. Tal atitude consiste na regra de ouro do mediador, característica que diferencia a mediação de outros mecanismos que igualmente visam à obtenção da autocomposição.

Para desempenhar bem o seu papel, o mediador deve demonstrar neutralidade, capacitação, flexibilidade, inteligência, paciência, empatia, sensibilidade, imaginação, energia, persuasão, capacidade para se distanciar de ataques, objetividade, honestidade e perseverança, além de ser digno de confiança e ter senso de humor.

A confidencialidade da mediação é uma de suas características mais importantes, constituindo-se no maior dever do mediador. O custo da mediação é em muito inferior ao custo do processo judicial. Além de dispensar advogados (não quer dizer que os envolvidos não possam ser assistidos), o serviço do mediador dispensa estruturas complexas, bastando-lhe uma sala e uma secretária. Com relação a estrutura da sala, esta deve ser de preferência um ambiente tranqüilo, a 
parede pintada em cores suaves, ternas, aconselha-se a cor azul, por ser uma cor que transmite serenidade. As cadeiras devem ser dispostas em circulo e não deve haver nenhuma mesa no centro, para que o mediador não assuma alguma posição que indique superioridade em relação aos envolvidos.

Há, entretanto, casos em que não se recomenda a mediação, quando existe certo grau de desequilíbrio de poder entre os envolvidos. Neste caso, a interferência do Estado se apresenta como solução mais adequada.

Quanto as etapas do Processo de Mediação, os estudiosos mencionam que existem algumas. Importa dizer que, independentemente do método escolhido para o procedimento, a mediação sempre apresenta três etapas imprescindíveis: instalação, negociação e acordo.

O mediador utilizará várias técnicas de encaminhamento da mediação, esclarecendo aspectos deste encaminhamento de forma permanente, formulando perguntas, escutando atentamente as partes e seus representantes advogados, tomando notas, e poderá ouvir as partes ou seus advogados em separado, quantas vezes quantas forem necessárias, devendo, quando chegar o momento, encaminhar as propostas de uma parte à outra no intuito de alcançar um acordo, em geral escrito, que representará o resultado positivo da mediação.

No Brasil, existe o projeto de lei $\mathrm{n}^{\circ} 94$ de 2002, que trata da mediação, de autoria da deputada Zulaê Cobra Riberiro, foi aprovado na Câmara dos Deputados e encontra-se na Comissão de Constituição e Justiça do Senado. Existe também um anteprojeto de lei do Instituto Brasileiro de Direito Processual e da Escola Nacional de Magistratura, apresentado ao Ministro da Justiça, no ano de 2002. Atualmente existe um novo projeto de lei, numa versão consensuada, pois reúne os autores do projeto e do anteprojeto acima mencionados, onde, por iniciativa do Secretário da Reforma do Judiciário, juntamente com o Ministro da Justiça, foi amplamente debatido em audiência pública, na data de 19 de setembro de 2003, e além de contar com as presenças dos autores do projeto e anteprojeto iniciais, participaram também os membros do Poder Judiciário da Advocacia e das instituições, entidades e pessoas especializadas em mediação. Os participantes apresentaram sugestões e algumas foram acolhidas pela comissão conjunta e passaram a incorporar o texto final do novo projeto.

Hodiernamente, é sabido que através do Provimento $n^{\circ} .7$ de 7 de maio de 2007 do Conselho Nacional de Justiça põe em prática a mediação incidental, sempre tendo como escopo a observância dos artigos $5^{\circ}$, inciso XXXV e $37^{\circ}$ de Constituição da República Federativa do Brasil, define medidas de aprimoramento relacionadas ao sistema dos juizados especiais. Percebe-se então, a merecida importância dos Juizados Especiais como um portal de abertura para a mediação. 
Com o advento da Resolução $n^{\circ} 125$, de 25 de novembro de 2010 do Conselho Nacional de Justiça, tivemos a definição de uma política nacional de "tratamento adequado dos conflitos de interesses no âmbito do Poder Judiciário" e disciplina o modo de funcionamento, bem como estabelece os prazos para que os Tribunais instalem os Centros Judiciários de Solução de Conflitos e Cidadania, além de Núcleos Permanentes de Métodos Consensuais de Solução de Conflitos, e ainda, estabelece o Código de Ética que Conciliadores e Mediadores Judiciais deverão se submeter.

No âmbito judiciário, as sessões de mediação são chamadas de audiência de mediação, onde, no dia e hora, previamente marcadas as partes comparecem e o juiz inicia a sessão, ao final é redigido um termo de audiência, em que consta a realização do acordo, e em caso de não ser possível o acordo, a parte promovente fica advertida que,querendo iniciar um procedimento judicial, deverá retornar àquela Unidade Judicial.

A título de ilustração - por assim dizer - tomamos como parâmetro a Segunda Unidade do Juizado Especial Cível e Criminal em Fortaleza, onde já é uma realidade as audiências de Mediação. As primeiras audiências foram feitas pelo Magistrado daquela Unidade, que uma vez por mês realiza as audiências de mediação, haja vista que o Tribunal de Justiça local ainda se encontra em fase de implantação das diretrizes do Provimento $n^{\circ} 7$, e da Resolução $n^{\circ} 125$, ambos do Conselho Nacional de Justiça.

Não existe ainda uma definição acerca da figura do mediador. Esta Unidade judicial conta com um sistema totalmente virtualizado, chamado projudi, e possui atualmente 862 processos. Ainda tramitam alguns processos físicos cíveis, num total de 207 e 198 processos criminais. É importante mencionar que desde o ano 2007 vem sendo realizadas mediações "informais" neste juizado, tendo obtido resultados excelentes, além da aceitação e procura, por parte da comunidade. Entretanto, devido a informalidade do procedimento, não haviam estatísticas. Apenas após a institucionalização da mediação nos JECCs, o trabalho realizado nesta Unidade judiciária possui estatísticas, vejamos: "Na data de 18 de Março de 2011, foram marcadas duas mediações que restaram prejudicadas em virtude da ausência da parte promovida.".

Cumpre destacar que o Tribunal de Justiça do Ceará, atendendo a determinação do Conselho Nacional de Justiça, através do Provimento n ${ }^{0} 3 / 2011$, institui o Núcleo para Solucionar Conflitos por meio da Mediação, e designa os integrantes que dele participarão, por meio da portaria 281/2011 deste Tribunal. De acordo com este documento será implantada a Central de Mediação, que funcionará no Palácio da Justiça e ficarão a cargo da coordenação deste núcleo, um desembargador e um juiz do JECCs, além de uma equipe de apoio, multi- 
disciplinar, que auxiliarão no funcionamento da Central, que deverá iniciar seus trabalhos no fórum Clóvis Beviláqua. Em etapa posterior, o setor implantará a mediação nos Juizados Especiais Cíveis e Criminais, e, por último, nas Comarcas do interior do Estado.

\section{Mediação Incidental e Mediação Parajudicial}

Considerando que não faz parte da cultura do brasileiro a busca espontânea dos mecanismos de solução dos conflitos, é que a relação com a justiça se faz necessária. Em decorrência desse aspecto cultural, o número de mediadores e de interessados em praticar essa atividade ainda é inexpressivo em face das dimensões e da população do país. São praticamente inexistentes os cursos de formação, haja vista que são importantíssimos para o fomento dessa atividade.

Quanto à mediação parajudicial, trata-se da mediação que já é praticada espontaneamente pelos chamados, mediadores independentes, pois, embora não haja nenhuma lei prevendo tal atividade, ela não é nem poderia ser vedada, pois constitui mero auxílio a pessoas, que são livres para aceitar ou não o mecanismo. O que difere a mediação parajudicial da mediação incidental que é a relação com o Poder Judiciário e com a Ordem dos Advogados.

\section{Conciliação}

No Brasil a expressão conciliação tem sido vinculada principalmente ao procedimento judicial, sendo exercida por juízes, togados ou leigos, ou por conciliadores bacharéis em direito, e representa, em realidade, um degrau a mais em relação à mediação, isto significando que o conciliador não se limita apenas a auxiliar as partes a chegarem, por elas próprias, a um acordo, mas também pode aconselhar a tentar induzir as mesmas a que cheguem a este resultado, fazendo-as divisar seus direitos, para que possam decidir mais rapidamente.

Autocomposição é um vocábulo mais preciso, pois indica o resultado. Por esta razão é mais apropriado falar de conciliação apenas no sentido da atividade tendente a incentivar e coordenar um acordo entre partes. A conciliação pressupõe a atividade de um terceiro, enquanto que a autocomposição tanto pode ocorrer como conseqüência do incentivo ou orientação de um terceiro como pode ser conseqüência da atividade dos próprios interessados.

Entendemos que a conciliação tem por escopo obter um acordo entre as partes e que, normalmente, o acordo obtido é do tipo transativo, o estudo dos dois institutos, conciliação e transação, tem sido, muitas vezes, elaborado em conjunto, com grande dificuldade de compreensão. Na realidade, para o direito processual, mais importante é o estudo dos mecanismos operados para atingir a transação ou outra forma de autocomposição. No caso, a conciliação. 


\subsection{Conciliação Judicial e Extrajudicial}

Considera-se conciliação extrajudicial somente aquela que se desenvolve sem que haja processo judicial em curso, sendo denominada pré-processual quando sobrevém o processo. A conciliação concomitante ao processo, ainda que seja levada a efeito por órgãos não-jurisdicionais (conciliadores), é considerada conciliação judicial, porquanto se considera conciliação o mecanismo de solução de conflitos tendentes à obtenção da autocomposição desenvolvida por órgãos judiciais ou parajudiciais.

A conciliação extra e pré-processual é uma alternativa ao processo e um meio de evitá-lo, sendo grande a sua relevância não só por se constituir em um meio alternativo de solução dos litígios, mas, sobretudo, por evitar o processo. Todavia, há de se ressaltar que não há qualquer impedimento legal ou lógico para que se realize atividade de aproximação das partes fora do processo e do ambiente judicial, como atividade informal ou estruturada em mecanismo diverso, como por exemplo, a mediação.

A conciliação judicial é concomitante ao processo e desenvolvida no ambiente judicial. Pode ser levada a efeito pelo próprio juiz da causa ou por um conciliador. A primeira faz parte do procedimento e encontra-se prevista em diversos dispositivos da legislação processual brasileira, desde a Consolidação das Leis do Trabalho, de 1943, até recente alteração do Código de Processo Civil, tratando da conciliação na audiência preliminar. A conciliação judicial desenvolvida por conciliador assemelha-se àquela extrajudicial e prévia.

A figura central, neste mecanismo, é o conciliador. As experiências que se verificam hoje, no Brasil, indicam muito mais a atividade conciliatória concomitante ao processo do que pré-processual. Diversos tribunais têm instituído quadro de conciliadores, com o objetivo de tentar resolver as demandas já propostas, apresentando êxito razoável. Particularmente, isso já está ocorrendo no Tribunal de Justiça do Ceará, existe também a proposta de se fazer seleção para a escolha dos conciliadores.

Enquanto a conciliação pré-processual possa dispensar a homologação judicial posterior, a conciliação judicial concomitante ao processo resulta necessariamente no retorno dos autos ao juiz, seja para a atividade homologatória seja para o prosseguimento do processo.

Ao contrário do que se disse anteriormente a respeito da conciliação pré-processual, a conciliação realizada após a propositura da demanda pode evitar o labor valorativo do juiz, mas não evita o processo e a atividade jurisdicional em sentido amplo. 


\section{Distinção entre Mediação e Conciliação}

Tarefa mais árdua é estabelecer os traços distintivos entre mediação e conciliação, especialmente porque, ao adotar essa ou aquela nomenclatura para alguma atividade, os diversos organismos não cuidam de adotar terminologia coerente e uniforme, considerando as experiências anteriores de outros modelos. Portanto, a terminologia adotada nos diversos países deve ser objeto de observação e estudo, mas jamais poderá ser considerada como critério definitivo para distinção entre conciliação e mediação.

Não obstante ambas atividades apresentarem características em comum, todavia, a principal distinção entre os dois mecanismos não reside em seus dirigentes, mas sim no método adotado: enquanto o conciliador manifesta sua opinião sobre a solução justa para o conflito e propõe os termos do acordo, o mediador atua com um método estruturado em etapas sequenciais, conduzindo a negociação entre as partes, dirigindo o "procedimento", mas abstendo-se de assessorar, aconselhar, emitir opinião e de propor fórmulas de acordo.

\section{F- O APRIMORAMENTO DA JUSTIÇA EstaduAL - A MEDIAÇÃo E A Conciliação na Segunda Unidade do Juizado Especial Cível e Criminal}

Inicialmente, cumpre observar que profundas alterações têm sido adotadas no processo e no aparelho judicial brasileiro, visando à efetividade do processo e desmistificando cânones antigos, como a tripartição do processo (conhecimento, execução e cautelar).

Outras alterações significativas operam-se fora do âmbito dos códigos processuais, como a Lei dos Juizados Especiais Cíveis e Criminais - Lei $n^{\circ} .9 .099$, de 26 de setembro de 1995 .

Essas modificações legislativas devem ser valorizadas, pois proporcionam melhor racionalização da Justiça, objetivando a celeridade e economia processuais. Ao lado dessas reformas, iniciativas de naturezas diversas devem ser igualmente aplaudidas, tais como o aumento do número de juízes, sua formação e capacitação; a informatização e a melhoria da infraestrutura administrativa dos órgãos judiciais. Porém, quanto aos servidores ainda há muito que se fazer quanto ao contingente e capacitação.

Surgem então ideias renovadoras propondo que sejam instituídos meios de realização da justiça diversos daqueles apontados como tradicionais ou ordinários e que proporcionem a efetiva pacificação social: são os denominados meios alternativos de solução de conflitos, objeto de estudo deste trabalho. 
De qualquer forma, para uma política de solução de conflitos não se pode abrir mão da reforma das leis processuais nem da adoção de meios alternativos, pois todos (jurisdição estatal e meios alternativos) são meios adequados para a restauração da paz social.

Atualmente observa-se uma crise de credibilidade pela qual passa não só o Judiciário, mas as instituições públicas de modo geral. No ano de 2007, uma pesquisa feita pela Associação dos Magistrados Brasileiros apontou os Juizados Especiais como a terceira instituição pública de maior credibilidade no País.

Hodiernamente, o que se verifica é a necessidade de capacitação nos juizados, desde um juiz atuante, qualificado, desburocratizado, por assim dizer, conhecedor dos institutos que ali podem ser postos em prática - mediação e conciliação - bem como os servidores que ali trabalham, pois os juizados são o espelho do Judiciário, haja vista que é lá onde se verifica a efetiva e rápida prestação jurisdicional.

Não obstante o fato de ainda se encontrar em fase de implantação da resolução 125 do CNJ, já são feitas mediações neste Juizado Especial. Entretanto, como ainda não há uma definição acerca do mediador, as audiências de mediação estão sendo realizadas pelo próprio magistrado coordenador do projeto, haja vista que tem conhecimento da área.

No âmbito judiciário as sessões de mediação são chamadas de audiências de mediação, onde, no dia e hora previamente marcadas, as partes comparecem e o juiz inicia a sessão. Ao final, é redigido um termo de audiência, em que consta a realização do acordo, e em caso de não ser possível o acordo, a parte promovente fica advertida que, querendo iniciar um procedimento judicial, deverá retornar àquela unidade judicial.

Tomamos como parâmetro a $2^{\mathrm{a}}$ Unidade do Juizado Especial Cível e Criminal em Fortaleza, onde as audiências de mediação já são uma realidade. As primeiras audiências foram feitas pelo magistrado daquela unidade, que uma vez por mês realiza as sessões de mediação, pois em virtude do Tribunal de Justiça local ainda se encontrar em fase de implantação das diretrizes do Provimento $\mathrm{n}^{\circ} 7 \mathrm{e}$ da Resolução 125, ambos do CNJ, não existe ainda uma definição acerca da figura do mediador. $\mathrm{O}$ trabalho realizado nesta unidade judiciária já possui estatísticas. Vejamos: "Na data de 18 de março de 2011 foram marcadas duas mediações que restaram prejudicadas em virtude da ausência da parte promovida."

Nessa unidade, as ações que ocorrem com maior frequência são: ações de cobrança de dívidas e taxas condominiais e reparação de danos referente a roubos de carros, motos e bicicletas. Vale ressaltar que esses fatos ocorrem nos estacionamentos dos mercantis da redondeza, bem como ações junto às empresas 
fornecedoras de água e energia elétrica. Outras ações que tramitam dizem respeito a questões de vizinhança ou demarcação de propriedades. Estas últimas geram grandes celeumas, pois na área de abrangência da competência territorial, muitos imóveis são decorrentes de invasões, e outros não possuem registros cartorários próprios devido ao baixo poder aquisitivo para efetuar o pagamento das custas e taxas cartorárias, ou mesmo pelo total desconhecimento sobre a necessidade de registro e escritura de seus imóveis.

Em 28 de abril de 2011, foram marcadas seis mediações, sendo que obteve-se acordo em três, ficando apenas uma sem a realização de acordo, e nas duas restantes a correspondência não voltou a tempo, ficando dessa forma sem saber se a parte promovida havia sido comunicada. Portanto, foi obtido $50 \%$ (cinquenta por cento) de acordo.

No que pertine às conciliações no Juizado, são realizadas pela conciliadora e pela auxiliar de conciliação, a primeira por indicação do magistrado e nomeada pelo Diretor do Fórum, para um mandato de dois anos, renovável por igual período. A segunda é servidora da Justiça, graduada em Direito, sendo nomeada pelo juiz titular do Juizado dentre os servidores aptos.

Outrora, sem a auxiliar de conciliação eram realizadas diariamente cerca de doze audiências de conciliação e cinco de instrução. Atualmente, com a auxiliar de conciliação trabalhando simultaneamente com a conciliadora, podem vir a ser realizadas até cerca de vinte audiências de conciliação por dia - este quantitativo depende da demanda.

O ambiente interno é refrigerado, e o mobiliário passou por recente reforma. Nota-se a preocupação em apresentar um caráter mais acolhedor com a utilização de aparelho de televisão na recepção, decoração discreta e nas salas de conciliações e audiências o uso da aromaterapia e musicoterapia está sendo implantado. Essas são formas de humanização do espaço público, atualmente em prática em centros urbanos mais avançados e com concepções de administração mais sensíveis em dimensionar e reconhecer as diferenças suscetíveis a cada tipo de público correspondente.

A utilização de tais métodos tem como objetivo harmonizar o ambiente, favorecendo um maior bem-estar e compreensão entre as partes envolvidas em um litígio, de modo a contribuir para uma conciliação mais profícua. Muito embora, para os que compreendem a dinâmica e filosofia de um juizado especial que dá ênfase aos institutos da mediação e conciliação é sabido que os doutrinadores insistem no uso de tais práticas a começar pela tonalidade das paredes dos ambientes e utilização de mobiliário próprio, somados às demais terapias de ambientalização moderna, tais como músicas, aromas, jardins, águas, cores, quadros, climatização etc. 
Esta reestruturação, somada aos objetos de acervo pessoal do magistrado e demais práticas com custeio próprio, vem gerando um excelente resultado na comunidade presente naquela Unidade jurisdicional. Ressaltou ainda o magistrado, que existe projeto de implementação de atividades de dinâmicas de grupos com a equipe de trabalho, através da consultora em Neurolinguística, que voluntariamente acolheu o pedido e apresentou plano de trabalho nessa área.

A Segunda Unidade do Juizado Especial Cível e Criminal é formada por uma equipe de dezesseis pessoas, sendo composta por um Juiz de Direito, um Promotor de Justiça, uma auxiliar da promotoria, três policiais militares, um estagiário voluntário, uma diretora de secretaria, um analista judiciário, uma conciliadora, uma auxiliar de conciliação, uma servente e quatro atendentes judiciárias.

Pela pesquisa de campo realizada neste Juizado percebem-se várias peculiaridades decorrentes da localidade em que o Juizado se situa. Outra questão tratada pelo magistrado diz respeito ao critério de seleção dos vinte conciliadores nomeados por ato do Tribunal de Justiça. Foi proposta a ideia de que seja feita uma seleção pública para os cargos de conciliadores, encerrando a celeuma sobre quais critérios norteadores definem os capacitados para o exercício de tão nobre função, que é a de conciliar.

Outro aspecto de grande importância a ser considerado pelo Juiz Titular da Segunda Unidade diz respeito ao fato de que os membros integrantes do Tribunal do Povo - instância superior em grau de recurso das decisões julgadas nos Juizados Especiais - devem ser juízes de Direito nomeados pelo Tribunal de Justiça para um período de dois anos, podendo ser renovado a critério do próprio Tribunal de Justiça. Entretanto, não obstante o fato de serem juízes capacitados em suas funções jurisdicionais, mas por serem afeitos à prática constante de suas respectivas varas da processualística cíveis e criminais, muitas vezes apresentam dificuldades em compreender a estrutura processual e os princípios norteadores da Lei 9.00/95 - Lei dos Juizados Especiais Cíveis e Criminais - gerando impasse em vários nos acórdãos. Entende-se ser conveniente que o Tribunal de Justiça do Ceará, através da Escola da Magistratura do Estado do Ceará, crie um breve Curso de Aprimoramento em matéria de Juizados Especiais capacitando-os para o exercício em segunda instância.

Nas palavras da conciliadora daquela Unidade, assevera que o juiz é o reflexo, ou seja, ele imprime a sua maneira de conduzir as ações, o seu modo de julgar. Ocorre que, infelizmente, existem pessoas que tentam tirar proveito das facilidades da Lei 9.099/95. Um exemplo disso é que, pelo fato de não ser necessário a presença de advogado, indivíduos especializadas em instruir erronea-mente pessoas a ingressarem com ação, em geral pedindo reparação de danos, quando elas não sabem quantificar o dano que sofreram ou ainda pior, confundem 
o significado de dano com mero aborrecimento. Um exemplo disso, foi de uma pessoa que ingressou com ação de reparação de dano porque havia comprado uma torta de frango e ela - a torta - estava torta.

Evidencia-se como fator prejudicial, a falta de conhecimento e valoração do instituto da mediação e conciliação, por parte do jurisdicionado, e muitas pessoas não reconhecem a verdadeira importância e seriedade desses institutos.

Pelo valor das ações ali intentadas até o limite de vinte vezes o valor do salário mínimo, não se requer advogado, podendo a parte interessada comparecer ao balcão de atendimento e relatar o seu caso, e este ser reduzido a termo. No entanto, é necessário que o servidor que faz este atendimento esteja apto a prestar todas as informações necessárias, pois a pessoa que ali se apresenta é, em geral, totalmente leiga, sendo necessárias informações precisas, em linguagem clara, acessível, de fácil compreensão para que a mediação ou a conciliação venha a obter êxito. Um exemplo disso é informar ab initio o promovente sobre as peculiaridades da lei 9.099/95.

A citação é feita por carta (AR), e o carteiro vai até o endereço do demandado (que foi previamente fornecido e confirmado pelo demandante), e assim o fará por três dias consecutivos e em horários alternados, não encontrando a pessoa por incompatibilidade de horário ou porque ele está se ocultando, deixará um aviso para que ele compareça aos correios para resgatar a citação. Se o motivo de não encontrar o demandado for porque ele mudou de endereço, levará de volta a citação e o conciliador intimará o demandante para que este apresente o novo endereço em 15 (quinze) dias. Se ainda assim o demandante confirmar que o endereço está correto, então o oficial de justiça fará a citação. Mensalmente é feita uma estatística e enviada para o Tribunal de Justiça, que faz o controle. Só figuram nessa estatística as audiências realizadas, isto é, aquelas em que as duas partes compareceram (promovente e promovido).

No Juizado em epígrafe, a realização deste trabalho possui algumas estatísticas bastante favoráveis, conforme demonstra a breve estatística a seguir:

No mês de novembro de 2010 foram designadas 182 audiências de conciliação - somatório da conciliadora e da auxiliar de conciliação e contabilizando-se apenas as audiências realizadas - 77 audiências realizadas, 49 acordos, totalizando percentual de $63 \%$. No mês de dezembro de 2010 foram designadas 71 audiências de conciliação - somatório da conciliadora e da auxiliar de conciliação e contabilizando-se apenas as audiências realizadas - 30 audiências realizadas, 12 acordos, totalizando percentual de $40 \%$. No mês de janeiro de 2011 foram designadas 105 audiências de conciliação - somatório da conciliadora e da auxiliar de conciliação e contabilizando-se apenas as audiências realizadas - 37 audiências 
realizadas, 17 acordos, totalizando percentual de 45,9\%. No mês de fevereiro de 2011 foram designadas 91 audiências de conciliação - somatório da conciliadora e da auxiliar de conciliação e contabilizando-se apenas as audiências realizadas - 37 audiências realizadas, 15 acordos, totalizando percentual de 40,5\%. No mês de março de 2011 foram designadas 163 audiências de conciliação - somatório da conciliadora e da auxiliar de conciliação e contabilizando-se apenas as audiências realizadas - 68 audiências realizadas, 30 acordos, totalizando percentual de 44,1\%.

No ano de 2006 aconteceu a primeira mobilização em prol da conciliação. Trata-se do dia Nacional da Conciliação, realizado no dia 8 de dezembro, data em que se comemora o dia da Justiça. Todas as Varas e Juizados Especiais realizaram audiências de conciliação, o dia inteiro. Este evento mobiliza juízes, promotores de justiça e servidores para a realização do maior número possível de conciliações. Convém mencionar que a justiça cearense no ano de 2007 realizou a $1^{\text {a }}$ Semana da Conciliação - de 3 a 8 de dezembro, com a mesma estrutura da mobilização do Dia Nacional da Conciliação - a realização do maior número possível de conciliações. Desde então, todos os anos existe esta mobilização nacional em prol da conciliação.

\section{Considerações Finais}

É fundamental a adequada formação e permanente preparação do terceiro imparcial que irá participar de algum dos mecanismos para a obtenção da autocomposição. O êxito estará garantido à medida que o terceiro imparcial tiver capacidade para interpretar corretamente as expectativas dos envolvidos. Portanto, de forma a atingir um ponto de encontro que satisfaça as exigências de todos.

Vale ressaltar que no processo de solução extrajudicial de disputas não utilizamos o termo "partes" e sim "assistidos".

A formação do advogado, igualmente, é essencial e este necessita de treinamento técnico específico para atuar como negociador de seu cliente, ou seja, de forma consciente na conciliação.

A amplitude de objetivos leva à consideração de proporcional amplitude de aplicação dos meios alternativos, que se constituem em um sistema multiportas, com alternativas adequadas a cada espécie de conflito. Os meios de solução dos conflitos, ordinários ou alternativos, são eficientes para compor situações jurídicas de toda ordem, quer tenham natureza civil, penal ou administrativa. Qualquer que seja o campo do Direito onde esteja situado o conflito, sua solução é sempre possível e os meios para atingi-la são diversos. O ordenamento legal, por vezes, limita determinada forma de solução apenas a alguns tipos de litígio. Não se pode, com isso, afirmar que tecnicamente existia restrição a que todo e qualquer 
conflito seja passível de solução por uma determinada forma, seja aquela apontada como ordinária, seja qualquer uma das denominadas alternativas. Há meios adequados à solução de cada tipo de conflito de interesses e deve haver liberdade de escolha pelos próprios envolvidos do meio que entenderem mais adequados.

Um sistema de solução dos conflitos é eficiente quando conta com numerosas instituições e procedimentos que permitem prevenir e solucionar a maior parte das controvérsias com o menor custo possível, partindo da necessidade e interesse das partes.

"Da justiça estatal para a justiça alternativa" - é um caminho de transformação e mudança social, que transforma a cultura impositiva em uma cultura de consenso.

Todavia, ainda permanece a histórica resistência de algumas corporações à adoção dos mecanismos extrajudiciais para a obtenção da autocomposição. Temos como exemplo alguns magistrados, advogados e promotores de justiça. Pois, de um lado, alguns juízes sentem seu poder reduzido por deixar de exercê-lo em todos os litígios. De outro, os advogados apontam como falha do sistema alternativo a dispensa de sua participação obrigatória. No campo penal, enquanto o Ministério Público demonstra temor da impunidade (como se hoje esse fenômeno não se verificasse), os advogados relutam em aceitar a aplicação da pena sem que seja emanada de um sistema impositivo. Verifica-se, pois, que a adoção de um sistema alternativo, também chamado de multiportas, é uma opção política, que balança os alicerces de profundos interesses já sedimentados e, sendo o sistema jurídico fechado e complexo, afasta a sociedade da discussão e confere ao tema a chancela de técnico.

Ademais, faz-se necessário a consciência de que o tema deixe de ser discutido apenas internamente, dentro dos tribunais, mas que ganhe mais abrangência por um debate nacional descentralizado, pois só assim conheceremos o real posicionamento de toda a sociedade acerca do tema.

Essas considerações são importantes para que todos os envolvidos conheçam o sistema antes de optarem por este ou aquele mecanismo de solução de conflitos. Sua adoção pode trazer vantagens ou desvantagens, a depender do caso e da situação do envolvido. O certo é que, sendo um sistema múltiplo e optativo, sempre que adotado há de proporcionar vantagens aos envolvidos e, diretamente, a toda a sociedade, que se torna mais saudável à medida que seus conflitos são efetivamente resolvidos. Mais certo ainda, é que a autocomposição proporciona uma melhor adaptação dos envolvidos com a solução do conflito. 


\section{REFERÊNCIAS}

BACELAR, Roberto, Juizados Especiais: a nova mediação paraprocessual. São Paulo: Revista dos Tribunais, 2004.

DINAMARCO, Cândido Rangel. A Reforma do Código de Processo Civil. 2. ed. São Paulo: Malheiros, 1995.

FERNANDES, Antônio Scarance; GRINOVER, Ada Pellegrini; GOMES FILHO, Antônio Magalhães; GOMES, Luis Flávio. Juizados Especiais Criminais. 3. ed., São Paulo: Revisa dos Tribunais, 1999.

. "Os métodos alternativos de solução de conflitos no quadro do movimento universal de acesso à justiça." Revista Forense. Rio de Janeiro. Vol. 326, 1994.

. "Aspectos constitucionais dos juizados especiais de pequenas causas." In: Watanabe Kazuo (coord.) Juizados especiais de pequenas causas. São Paulo: Revista dos Tribunais, 1995.

. Manual de pequenas causas. São Paulo: Revista dos Tribunais, 1986.

GARCEZ, José Maria Rossani. Negociação, ADRs, Mediação, Conciliação e Arbitragem. 2. ed., Rio de Janeiro: Lumen Juris, 2004.

PASSOS, José Joaquim Calmon de. Comentários ao Código de Processo Civil. 8. ed. Rio de Janeiro: Forense, 1998, vol. III.

SALES, Lilia Maia de Morais. Mediare - Um guia prático para mediadores. 2. ed., Fortaleza: Universidade de Fortaleza, 2004.

SELVA, Alessandra Gomes do Nascimento. Técnicas de Negociação para Advogados. São Paulo: Saraiva, 2002.

. "Princípios e critérios no processo das pequenas causas." In: Watanabe

Kazuo (coord.) Juizados especiais de pequenas causas. São Paulo: Revista dos Tribunais, 1995.

. “Conciliação e juizados de pequenas causas.” Revista dos Tribunais. São Paulo, 1999.

. "Deformalização do processo e deformalização das controvérsias." Novas tendências do direito processual. São Paulo: Forense Universitária, 1990.

URY. Willian L. Como chegar ao sim Rio de Janeiro: Imago, 1994.

VEZZULLA, Juan Carlos. Mediação: Guia para usuários e profissionais. São Paulo: IMAB. 2001. 
VEZZULLA, Juan Carlos. A mediação de conflitos com adolescentes autores de ato infraconal. Florianópolis: Habitus, 2006.

WARAT. Luis Alberto. O ofício do mediador. V. 1. Florianópolis: Habitus, 2001. Sítios eletrônicos consultados:

www.cnj.org.br

www.tjce.org.br

MEDIATION AND CONCILIATION-AN EXPERIENCE IN FORTALEZA, BRAZIL

Abstract: This essay focuses briefly on the practice of mediation and conciliation techniques in the $2^{\text {nd }}$. Unit of the Special Courts in Fortaleza (Ceará, Brazil). It was made an empyrical research that evaluated the aplicability of such techniques, that proved quite successful, considering the changes of paradigms in Brazilian society and, of course, in the Judiciary system.

Keywords: Mediation. Conciliation. Alternative dispute resolution. Special courts.

Data de recebimento: nov/2010 - Data de aprovação: jan/2011 